\title{
O Que é Ciência? \\ Concepções de Licenciandos em Ciências Biológicas e Química
}

\author{
Andrea Inês Goldschmidt ${ }^{1}$ \\ Nathália Vieira Silva ${ }^{2}$ \\ Jenyffer Soares Estival Murça ${ }^{3}$ \\ Brucce Sanderson Prado de Freitas ${ }^{4}$
}

\section{Resumo}

0 objetivo deste trabalho foi identificar e analisar a presença das concepções sobre a Natureza da Ciência (NdC) entre acadêmicos dos cursos de Graduação (Licenciatura) em Ciências Biológicas e Química, da Universidade Federal de Goiás e a partir desta, analisar os contextos epistemológicos que a cercam. A pesquisa foi aplicada a 30\% dos acadêmicos de ambos os cursos que já tivessem concluído as disciplinas epistemológicas e/ou filosóficas da Ciência, em investigação realizada no Projeto Pedagógico do Curso. 0 instrumento de pesquisa constou da caracterização dos sujeitos da pesquisa e da solicitação aos acadêmicos para que produzissem um desenho mediante a seguinte afirmação: "Desenhe o que representa Ciência para você". Foram elencados três domínios de análise: 1) Ciência representada pelo ambiente que a compõe; 2) Ciência representada pelos elementos integrantes à natureza específica de cada área e 3) Ciência representada pela imagem do cientista. Os resultados mostraram que a Ciência é tida principalmente como uma atividade experimental e quase

${ }^{1}$ Professora-adjunta no curso de Ciências Biológicas, Departamento de Zootencia e Ciências Biológicas, Universidade Federal de Santa Maria, Campus Palmeira das Missões; Programa de Pós-Graduação em Ensino de Ciências e Matemática, Universidade Federal de Goiás. andreainesgold@gmail.com

2 Acadêmica do curso de Ciências Biológicas, Universidade Federal de Goiás, Instituto de Ciências Biológicas. nathalia_184@hotmail.com

3 Acadêmica do curso de Ciências Biológicas, Universidade Federal de Goiás, Instituto de Ciências Biológicas. jenyfferstival@gmail.com

4 Licenciado em Biologia, Mestrando no Programa de Pós-Graduação Interunidades - Instituto de Biociências, Instituto de Física, Instituto de Química, Faculdade de Educação - Universidade de São Paulo. bruccesanderson@gmail.com 
específica de laboratório. Pode-se concluir ainda que a visão de Ciência é orientada de acordo com a maneira como a área se estrutura e pela forma com que ela se relaciona com seus objetos de estudo, mostrando uma visão fragmentada do conhecimento.

Palavras-chave: Natureza da ciência. Concepções. Ensino em ciências. Formação de professores.

\title{
WHAT IS SCIENCE? CONCEPTIONS OF UNDERGRADUATES (TEACHER TRAINING) IN BIOLOGICAL SCIENCES AND CHEMISTRY
}

\begin{abstract}
The aim of this research was identify and analyze the presence of views of Nature Science between academic undergraduate courses (teacher training) in Biological Sciences and Chemistry of the Federal University of Goiás. We analyze the epistemological contexts that surround it. The research was applied to $30 \%$ of the students of both courses which had completed the epistemological and/or philosophical disciplines of science, research conducted at the Pedagogical Course Project. The research instrument consisted by the characterization of the research subjects and the request to students to produce a drawing by the following statement: "Draw what is science for you." It was listed three areas of analysis: 1) Science represented by the environment that composes; 2) Science represented by the integral elements to the specific nature of each area; and 3) Science represented by the scientist image. The results showed that science is mainly taken as an experimental activity and almost specifically in laboratory. We infer that the views of science is oriented according to the way that scientific areas are structured and the way it relates with its objects of study, showing a fragmented view of knowledge.
\end{abstract}

Keywords: Nature of Science. Conceptions. Learning in Science. Teacher Training. 
A Natureza da Ciência ( $\mathrm{NdC})$ possui várias definições, mas de forma geral refere-se à Epistemologia da Ciência, a reflexões sobre a maneira como o conhecimento científico é produzido ou ainda aos valores e crenças presentes que o permeiam (LEDERMAN, 1992). A NdC apresenta como a Ciência é feita e com o que os cientistas trabalham. Sendo assim, está relacionada à prática de fazer Ciência e o conhecimento produzido (REISS, 2009).

Cachapuz et al. (2011) afirmam que a $\mathrm{NdC}$ pode contribuir para que os cidadãos possuam um arcabouço mínimo de conhecimentos científicos para problematizar as relações estabelecidas entre a Ciência-Tecnologia-Sociedade-Ambiente (CTSA). Comentam ainda que a Ciência impacta na vida de todos os cidadãos, sendo assim, as tomadas de decisão não podem se restringir ao domínio político e científico.

Diante disso, a NdC configura-se caminho para a educação científica. Para tanto, é necessário realizar discussões acerca da $\mathrm{NdC}$ no processo formativo daqueles envolvidos com a área da Ciência e que estarão à frente das discussões sobre a temática com a sociedade em geral. Considerando que os licenciandos da área de Ciências serão sujeitos importantes para divulgar e construir estas ideias com um grande grupo de indivíduos, compreendemos que eles devem ter a oportunidade de discutir e questionar as diversas visões e representações de Ciência que são veiculadas na sociedade. Nesse contexto, necessitam ainda desenvolver a capacidade de instigar seus futuros discentes à reflexão sobre o papel da Ciência na vida cotidiana. Assim, é oportuno garantir que os futuros profissionais da educação adquiram uma compreensão adequada da $\mathrm{NdC}$ (PETRUCCI; DIBAR URE, 2001) para que possam se posicionar diante das discussões que envolvem a Ciência e a Tecnologia, favorecendo o processo de alfabetização científica e tecnológica da população (CARVALHO, 2011).

Gil-Pérez, Vilches e Ferreira-Gauchía (2008) argumentam que professores e estudantes necessitam ter uma visão mais ampla do conhecimento científico, revelando-se este parte de um processo de alfabetização científica. Para tanto, visões não adequadas da Ciência precisam ser combatidas nos diferentes níveis de ensino. 
Currículos que não se renovam, disciplinas específicas com professores sem formação adequada à área, ausência de experiência em laboratórios ou envolvimento com práticas relacionadas ao fazer Ciência, entre outros fatores, configuram-se como barreiras para uma formação de professores que considerem visões adequadas da Ciência (OLIVEIRA, 2013). Assim, a Ciência tem-se apresentado com diferentes visões dentro dos espaços educativos. Algumas destas representações estão incorporadas ao imaginário popular concernente à Ciência e se afastam da prática científica, bem como da forma como se constrói o conhecimento científico e tecnológico.

A formação inicial e a universidade deveriam configurar-se como momento e local oportuno para a desconstrução e a problematização dessas concepções entre os futuros professores. Uma vez não ressignificadas as concepções inadequadas de Ciência, estas podem continuar incorporadas em suas futuras práticas docentes. Isto pode fazer com que os profissionais da educação não só reafirmem as visões não adequadas de Ciência, como também dificultem os esforços para uma alfabetização científica contextualizada das próximas gerações de cidadãos. Como afirma Brickhouse (1989), são as concepções sobre o conhecimento científico dos professores que estarão presentes em sala de aula. Então, são estas que devem ser consideradas e ressignificadas. (Re)pensar a educação científica numa perspectiva da $\mathrm{NdC}$ envolve compreender as visões da Ciência dos professores de Ciências que influenciam o seu fazer docente, bem como suas possibilidades de intervenção na realidade social.

No que se refere às visões deformadas da Ciência e da Tecnologia de professores de Ciências, Cachapuz et al. (2011) salientam que o enfoque nos aspectos empíricos da atividade científica evidencia a imagem descontextualizada, individualista e elitista do cientista. Estas imagens traduzem-se em iconografias do cientista como homem da bata branca em um laboratório isolado, longe de fazer parte da sociedade, cheio de instrumentos e aparelhagens que poucos conhecem e sabem a utilidade, os quais o cientista manuseia para fazer experimentos e observações, em busca de "descobrir" algo. 
Essas imagens estereotipadas do cientista e da Ciência veiculadas na sociedade podem afastar os discentes dos objetivos traçados pelo professor de Ciências e dificultar o trabalho de construção do conhecimento científico em sala de aula (MESQUITA; SOARES, 2008). Cachapuz et al. (2011), ao discutirem as distorções nas representações de Ciência também destacam que visões empobrecidas podem gerar o desinteresse, quando não a rejeição, de muitos estudantes, o que pode tornar-se um obstáculo para a aprendizagem.

Nesse contexto surgiram as seguintes questões investigativas: Quais são as concepções de $\mathrm{NdC}$ dos licenciandos da área de Ciências da Universidade Federal de Goiás (UFG)? Na concepção dos licenciandos qual é o ambiente que a Ciência ocupa? A representação social de Ciência é verificável entre os licenciandos que já tenham cursado disciplinas que problematizam a $\mathrm{NdC}$ ?

A partir desses questionamentos sobre o tema em estudo, objetivamos com este artigo identificar e analisar a presença das concepções sobre $\mathrm{NdC}$ entre acadêmicos dos cursos de Graduação (Licenciatura) em Ciências Biológicas e Química, da Universidade Federal de Goiás, e a partir desta analisar os contextos epistemológicos que a cercam. Assim, o presente trabalho está organizado em quatro momentos: a apresentação de referenciais teóricos sobre a Natureza da Ciência, revelando estudos que demonstram visões não adequadas e a importância da educação científica neste contexto; a descrição o desenvolvimento metodológico do trabalho; a apresentação dos resultados e discussão dos participantes da pesquisa e na parte final as considerações finais e suas implicações para o ensino de Ciências.

\section{Referencial Teórico}

No que respeita à produção do conhecimento científico, Chalmers (1993) discorre e apresenta as limitações das diferentes formas como a Ciência é pensada e analisada. Em seu trabalho, o autor explora as principais correntes filosóficas desenvolvidas acerca das visões de Ciência. Utilizaremos esse escrito por considerarmos que as reflexões realizadas por Chalmers contemplam as 
principais visões de Ciência difundidas no meio acadêmico e, consequentemente, na construção do conhecimento científico. As visões de Ciência são as seguintes:

1. Indutivismo ingênuo: o conhecimento científico é obtido por meio da observação de experimentos ou fenômenos. Mediante uma observação são feitas afirmações singulares (se referem a uma ocorrência específica), que se verificadas em uma variedade ampla de condições, com um número de proposições para formar uma base de generalização e se não houverem contradições, são consideradas afirmações universais. Estas, por sua vez, referem-se "a todos os eventos de um tipo específico em todos os lugares e em todos os tempos" (p. 27). Sendo assim, quanto mais aperfeiçoarmos nossas observações e experimentos, maior é a quantidade de dados que nos permitem elaborar teorias e leis gerais. $\mathrm{O}$ crescimento da Ciência segundo essa visão é contínuo, acumulativo e elaborado no sentido de explicar e prever. Chalmers adverte que sempre existirá a possibilidade da próxima observação contradizer as afirmações universais. Afirma ainda que as proposições pautadas na observação são falíveis, uma vez que estas são passíveis de limitações tanto humanas (perceptivas) quanto instrumentais no que diz respeito à tecnologia utilizada. Dessa forma, a indução como método não pode garantir que determinada afirmação universal seja verdadeira.

2. Raciocínio lógico dedutivo: consiste na derivação das afirmações universais discutidas no subtópico anterior. Caso o cientista possua as afirmações universais basta utilizar de lógica para deduzir um determinado fenômeno sem a necessidade de experimentação. Para realizar este processo é necessário possuir duas premissas verdadeiras (duas afirmações universais) que não se contradigam para chegarem a um resultado. Por meio dessa abordagem objetiva-se prever e explicar os fenômenos, contudo encontramos aqui um problema. Caso uma das premissas não seja verdadeira ou contrária à outra, o raciocínio lógico não permite alcançar um resultado. Sendo assim, torna-se imprescindível realizar observações e experimentos com estas a fim de melhor esclarecê-las. Se considerarmos a fragilidade da elaboração das 
afirmações universais verificamos que sempre haverá a possibilidade cometer equívocos em relação às deduções, colocando em dúvida a fidedignidade dos conhecimentos advindos de propostas dedutivas.

3. Falsificacisonismo: foi elaborado pelo filósofo da Ciência Karl R. Popper (1969). Diferentemente do indutivismo e da dedução, esta visão de Ciência ressalta o papel da teoria como precedente da observação e da experimentação. As teorias são conjecturas especulativas ou suposições testadas por meio da observação e experimentação. As não corroboradas por testes são eliminadas e substituídas por uma teoria adaptada advinda de outras teorias corroboradas mediante experimentações. A teoria adaptada é a melhor solução possível do momento. Esta é obtida por tentativa e erro, conjectura e refutação. Para ser Ciência, a teoria tem de ser obrigatoriamente falsificável. Caso ela não seja, deve ser desconsiderada. Nessa perspectiva, nunca pode-se afirmar que uma teoria é verdadeira. Ela sempre é a melhor explicação do momento, pois à medida que surgem novos paradigmas e problemas, as teorias já falseadas devem ser testadas novamente, e caso não resistam, devem ser substituídas. Outra crítica refere-se ao fato de o falsificacionismo ser inadequado em termos históricos, dado que o abandono completo de teorias na constituição de explicações científicas não pode ser constatado de forma generalizada.

4. Programas científicos: proposto por Imre Lakatos (1974). Segundo essa visão, a teoria e a observação são dependentes uma da outra. Para Lakatos as teorias devem ser vistas como estruturas por três motivos: por meio do relato histórico é possível verificar que elas possuem tal aspecto; somente mediante teorias estruturadas os conceitos assumem sentido e o fato de a Ciência necessitar crescer. Somente com teorias estruturadas a Ciência tem a possibilidade de desenvolver programas que lhe permitam expandir-se. Os programas de pesquisa possuem uma heurística positiva (hipótese geral, núcleo infalível que o programa desenvolve) e uma heurística negativa (compõe um cinturão de hipóteses auxiliares). A primeira é infalseável. Caso um cientista modifique o núcleo ele está automaticamente abandonando o programa de pesquisa. A parte mutante da teoria é a heurística negativa em 
que as teorias subjacentes apoiam o núcleo. Nessa perspectiva, o autor afirma ainda que um programa de pesquisa não pode ser comparado com outro, pois cada programa deveria ser analisado segundo seus princípios. Assim sendo, um programa é relativo ao tempo que um programa consiga ser sustentado.

5. Revoluções Científicas: elaborado por Thomas S. Kuhn (1970). Segundo este autor, a Ciência progride por meio de revoluções científicas em que ocorrem rupturas de paradigmas. Para ele existe um momento de pré-ciência em que não há uma organização definida do paradigma. Quando este se consolida passa-se para um período denominado Ciência normal. Os cientistas trabalham arduamente durante esse momento até que o paradigma apresente problemas e não consiga mais sustentar os pressupostos básicos para explicar um fenômeno. Quando o paradigma entra em crise, a superação do problema acontece por meio de uma revolução científica. Esta traz consigo um novo paradigma e, consequentemente, uma nova Ciência normal. Esse movimento repete-se continuamente numa dinâmica de rupturas e o estabelecimento de novos paradigmas. Para Kunh, a caracterização acerca da Ciência que ele faz está para além de uma descrição. Ela é, segundo ele, uma teoria da Ciência, uma vez que explica as funções de diferentes componentes desta.

6. Anarquismo científico: proposto por Paul K. Feyeraband (1975). Este afirma em seus escritos que pela história podemos verificar a impossibilidade de explicar a Ciência por meio de regras metodológicas simples. Buscar descrevê-la, segundo o autor, é até prejudicial à Ciência, uma vez que a torna mais dogmática e restritiva sobre a forma de fazê-la. Nesse sentido, a escolha dos cientistas por uma teoria (ou um programa de pesquisa), em detrimento de outras(os) não pode ser pautada por regras impostas pela metodologia científica. Ou seja, vale-tudo quando se faz Ciência. Outro aspecto de sua visão faz referência à incapacidade de se comparar duas teorias rivais, uma vez que elas em geral não partilham das mesmas proposições de observação, bem como possuem contexto diferenciados em sua gênese. Segundo Chalmers (1993), a Ciência não é superior às outras formas de conhecimento e que sendo assim o indivíduo deveria ter a oportunidade de acesso e escolha sobre o conhecimento que mais se adequa as suas convicções. A Ciência 
não deveria ser imposta como conhecimento dominante, como é feito, por exemplo, nas escolas. Ele defende a liberdade de ideias e equiparação dos conhecimentos.

Como observamos anteriormente não existe um consenso absoluto por parte dos filósofos e epistemólogos da Ciência acerca de todos os detalhes referentes à prática de fazer Ciência e de produzir conhecimento científico. Seja porque cada um objetivou e/ou destacou um aspecto diferente da atividade científica, ou mesmo pela dificuldade de definir um único "Método Científico" que compreenda todo o domínio científico contendo suas relações com a sociedade. Entendemos que para construir uma visão mais adequada da $\mathrm{NdC}$ é necessário compreender as nuances dessas discussões associadas à pesquisa científica. Nesse contexto, conceber a $\mathrm{NdC}$ abarca o conjunto de saberes sobre princípios epistemológicos envolvidos na construção do conhecimento científico, incluindo as crenças e valores inerentes a este processo (LEDERMAN, 1992).

Para Gil Pérez et al. (2001), professores de Ciências durante sua formação científica em Biologia, Física ou Química, deveriam ter adquirido uma linguagem adequada da construção do conhecimento científico durante a formação inicial e, portanto, estariam aptos a discuti-la em suas aulas. As pesquisas têm mostrado, no entanto, que as concepções de professores e estudantes, incluindo de futuros docentes, não passam de uma visão "popular" da Ciência, associada a um suposto método científico, único, algorítmico, bem definido e até mesmo infalível (FERNÁNDEZ et al., 2002; GIL-PÉREZ et al., 2001).

Mesquita e Soares (2008) estudaram as visões de Ciência em desenhos animados e constataram que eles trazem como personagens principais meninos cientistas que, muito inteligentes, usam suas invenções e criatividade para resolver situações que vão desde problemas na escola até salvar o mundo de uma invasão alienígena, sempre associados a laboratórios e experiências. Em relação à natureza do conhecimento científico, os autores analisaram a presença de situações e verificaram que nos episódios a Ciência começa e se desenvolver a partir de problemas e está associada à atividade experimental. Outra visão analisada foi a de que somente é Ciência aquilo que for aceito por consenso, o que constitui uma das ideias centrais de Thomas Kuhn para o desenvolvimento 
científico. Também verificaram que alguns episódios apresentam uma visão positivista, que concebe a Ciência como solução para todos os problemas humanos e valoriza a tecnologia sem se preocupar com as dificuldades geradas com base nesta valorização (MESQUITA, 2006).

Foi estudado, ainda, pelos autores, o perfil do cientista representado nos episódios. Quanto à caracterização física e intelectual dos personagens, apresentam-se geralmente de jalecos, são garotos dedicados à Ciência e que sempre trabalham sozinhos em seus experimentos, sem contar com ajuda de outros cientistas. O cientista apresenta-se, desta forma, solitário em suas atividades. Isto configura uma visão individualista da Ciência, em que os conhecimentos científicos aparecem como obras de gênios isolados (FERNÁNDEZ et al., 2002). Outra observação que merece destaque é que o desenvolvimento científico é papel exclusivo do gênero masculino.

Apesar de não haver unanimidade entre os epistemólogos sobre o fazer Ciência, Fernández et al. (2002) e Gil-Pérez et al. (2001) concordam no que diz respeito a quais concepções não adequadas da $\mathrm{NdC}$ poderiam ser evitadas entre professores e estudantes. São elas:

1. Ciência empírica-indutivista e ateórica: é uma imagem "ingênua" da Ciência, socialmente disseminada e aceita que enfatiza o papel "neutro" da observação e da experimentação. Nesta perspectiva, os papéis que desempenham as hipóteses no processo de produção do conhecimento científico são ocultados. Aqui a Ciência é produzida com base em "descobrimentos" realizados por meio da observação e experimentação, repetidas várias vezes e em diferentes situações, a fim de se encontrar em todos os tempos a mesma conclusão. Os adeptos desta visão não reconhecem a contribuição das teorias anteriores ao processo de construção do conhecimento científico, sendo assim ateórica.

2. Ciência aproblemática e a-histórica (portanto dogmática e fechada): os conhecimentos já elaborados são transmitidos, sem demonstrar os problemas que lhe deram origem, sua evolução e as dificuldades encontradas. A Ciência é realizada mediante a execução de um "Método científico" rígido, infalível e exato que deve ser seguido de forma mecânica. Não há com isto 
referências aos desdobramentos, evolução, limitações, idas e voltas que as teorias científicas tiveram (ou ainda têm) ao longo da História. Não é (são) assinalado(s) assim o(s) contexto(s) no(s) qual(is) foram desenvolvidas, tampouco os questionamentos que estão na origem da construção dos conhecimentos científicos. Nesta visão, o professor apresenta Ciência omitindo aspectos relevantes para sua compreensão.

3. Ciência acumulativa - linear: o conhecimento científico é apresentado de forma simplista. Nesta concepção, o ensino reforça a visão linear, uma vez que não mostra como os conhecimentos foram construídos. Apresenta-o como o fruto de um processo acumulativo ao longo dos tempos. Esta visão oculta a complexidade do fazer Ciência ignorando por vezes as crises, as remodelações e os confrontos de teorias rivais.

4. Ciência individualista e elitista: os conhecimentos científicos aparecem como obras de gênios isolados e que seus resultados são capazes de confirmar ou refutar uma teoria. Ignoram-se assim os trabalhos coletivos e as parcerias que são característicos do trabalho científico. Esta visão transmite também a ideia de que a Ciência é restrita a uma determinada classe social ou gênero, mostrando-se dessa forma discriminativa.

5. Ciência socialmente neutra: esquecendo-se as complexas relações entre Ciência, Tecnologia, Sociedade (CTS). A Ciência nesta visão está à parte da sociedade, havendo pouca ou nenhuma reflexão sobre as complexas relações que se estabelece com ela. Nem tão pouco os cientistas são relacionados aos impactos oriundos da Ciência, ou seja, são considerados isentos de quaisquer impactos que seu trabalho e decisões prevêem.

Outras concepções não adequadas de Ciências foram elencadas por Fernández et al. (2002) e Gil-Pérez et al. (2001), bem como por Cachapuz et al. (2011). Entendemos, contudo, que essas cinco são suficientes para desenvolver as discussões que nos propusemos a realizar em nossa pesquisa. Sendo assim, nos limitaremos a essas concepções e suas possíveis associações com o trabalho de Chalmers (1993) e os dados obtidos pela investigação. 


\section{Trajetória Metodológica}

A presente pesquisa apresenta uma investigação quantitativo-qualitativa, realizada com graduandos do curso de Licenciatura em Ciências Biológicas e em Química (integral e noturno) na Universidade Federal de Goiás. Foram pesquisados 78 graduandos de Ciências Biológicas e 43 de Química (correspondendo a $30 \%$ dos alunos dos cursos). Esta representação numérica de participantes foi utilizada por equivaler ao número de alunos que já haviam cursado disciplinas epistemológicas e/ou filosóficas da Ciência. Inicialmente foi realizado um estudo a partir do Projeto Pedagógico dos cursos com o intuito de investigar essas disciplinas. No curso de Química a disciplina com tal abordagem (Epistemologia da Ciência) ocorre no terceiro semestre para o turno diurno e no quarto para o noturno (UNIVERSIDADE..., 2009). Para o curso de Ciências Biológicas a disciplina (Filosofia da Ciência) é ofertada no primeiro semestre, e é de caráter obrigatório (UNIVERSIDADE..., 2003). Para fins de aplicação da investigação, optamos por padronizar a coleta em turmas a partir do quarto semestre, tendo todos os participantes já concluídos as disciplinas.

Os alunos foram convidados a participar da pesquisa, assinando um termo livre e esclarecido. O instrumento de pesquisa constou de duas etapas. A primeira delas foi a caracterização dos sujeitos da pesquisa (gênero, curso, turno do curso), não sendo solicitados os nomes para garantir o sigilo dos participantes. Num segundo momento foi pedido aos acadêmicos para que produzissem um desenho mediante a seguinte afirmação: "Desenhe o que representa Ciência para você”. Não houve qualquer tipo de explicação adicional. O tempo para fazer o desenho foi cronometrado em dois minutos.

O tempo, a coleta e análise de desenhos foram feitos a partir de uma adaptação das contribuições dos trabalhos de Böer (1993, 2007). Segundo a autora, o desenho é como uma fotografia externa que revela uma dimensão interna do indivíduo, e que é fruto das experiências de vida e aprendizagem que o aluno vivencia e recebe no seu contexto social. A resposta por meio dos desenhos contém um conjunto de elementos com simbologia própria, passíveis 
de interpretações. Acredita-se que nos símbolos há uma linguagem por meio da qual a pessoa pode comunicar a maneira como ela interioriza e percebe um determinado assunto, naquele momento.

Os desenhos foram recolhidos e analisados individualmente para o estabelecimento das categorias de análise a posteriori. Foram elencados três domínios de análise: (1) Ciência representada pelo ambiente que a compõe; (2) Ciência representada pelos elementos integrantes à natureza específica de cada área e (3) Ciência representada pela imagem do cientista. Estes puderam ser explorados individualmente, formando distintas categorias.

Neste estudo são discutidas as concepções relacionadas aos resultados e as respectivas porcentagens em que foram observadas nos desenhos (tratamento dos resultados). Com o objetivo de melhor apresentar e discutir os dados essas informações foram organizadas em tabela e figuras.

Optamos por aplicar a pesquisa em dois cursos distintos, no intuito de analisar as divergências e convergências entre os resultados das representações das duas Licenciaturas ligados à Ciência (Ciências Biológicas e Química), mas com especificidades distintas.

\section{Resultados e Discussões}

No que respeita às informações referentes ao curso em formação e à organização de disciplinas na matriz curricular relacionadas às temáticas epistemológicas e filosóficas, percebemos que os dois cursos pesquisados apresentam em sua formação, disciplinas nos primeiros anos do curso. No caso do curso de Ciências Biológicas, estas ocorrem no primeiro semestre, tanto no período diurno como no noturno. Já para o curso de Química ocorre no terceiro semestre para o curso diurno e no quarto semestre para o noturno. Para fins de análise, nos voltamos a verificar o que os Projetos Pedagógicos dos Cursos (PPC) apresentam em relação a essas disciplinas no que diz respeito às ementas, à bibliografia básica, carga horária e o núcleo de obrigatoriedade. 
Observamos no PPC da Química (UNIVERSIDADE..., 2009) que a disciplina de caráter epistemológico possui natureza obrigatória e carga horária de 32 horas semestrais, assim como a das Ciências Biológicas (UNIVERSIDADE..., 2003). A ementa da disciplina "Epistemologia da Ciência", de Química, aponta como objetivo discutir a "Natureza do Conhecimento Científico", bem como analisar as "Diferentes leituras de construção da Ciência". Há ainda a preocupação com a relação deste conhecimento com o do cotidiano, a escola e a importância de discussões sobre $\mathrm{NdC}$ na formação de professores (Quadros 1 e 2). Compreendemos com base nos referenciais utilizados neste trabalho (FERNÁNDEZ et al., 2002; GIL-PÉREZ et al., 2001), que existiu a preocupação por parte dos elaboradores desse documento como a problematização de possíveis visões não adequadas de Ciência dos sujeitos em formação. A bibliografia básica nos dá evidências disto, visto que são autores que apresentam e questionam as diferentes maneiras de fazer Ciência e produzir o conhecimento científico. Não iremos aqui esboçar a ideia de cada texto recomendado.

A disciplina "Filosofia da Ciência", do curso de Ciência Biológicas, possui como enfoques: o papel desempenhado pela teoria, hipótese, modelos, observação e experimentação na construção do conhecimento científico; as diferenças existentes entre Ciência e pseudociência; o reducionismo na Ciência e as ideias de paradigma, princípio antrópico e complexidade. A ementa não faz nenhuma menção sobre a relação das discussões epistemológicas e a formação de professores. Não foi encontrada no PPC do curso de Ciências Biológicas a bibliografia indicada para a disciplina, o que é importante e nos daria maior evidência das bases epistemológicas a que se propõe a disciplina. 
Quadro 1 - Distribuição de disciplinas relacionada aos Estudos

Epistemológicos de Ciências no curso de Licenciatura de Química (Integral e Noturno) da Universidade Federal de Goiás

\begin{tabular}{|c|c|c|c|c|}
\hline Curso & Disciplina & Período & Ementa & Bibliografia Básica \\
\hline $\begin{array}{l}\text { Química - } \\
\text { Licenciatura } \\
\text { (Integral e } \\
\text { Noturno)* }\end{array}$ & $\begin{array}{l}\text { Epistemologia } \\
\text { da Ciência } \\
(32 \mathrm{~h})- \\
\text { Núcleo } \\
\text { Específico } \\
\text { Obrigatório }\end{array}$ & $\begin{array}{l}\text { Terceiro } \\
\text { (Diurno) } \\
\text { Quarto } \\
\text { (Noturno) }\end{array}$ & $\begin{array}{l}\text { Natureza do } \\
\text { conhecimento } \\
\text { científico. } \\
\text { Diferentes } \\
\text { leituras da } \\
\text { construção } \\
\text { da ciência. } \\
\text { Conhecimento } \\
\text { cotidiano e } \\
\text { conhecimento } \\
\text { escolar. } \\
\text { O debate } \\
\text { epistemológico } \\
\text { na formação } \\
\text { inicial e } \\
\text { continuada de } \\
\text { professores. }\end{array}$ & $\begin{array}{l}\text { CHALMERS, A. F. O que é } \\
\text { a ciência afinal? São Paulo: } \\
\text { Editora Brasiliense, } 1993 . \\
\text { KUHN, T. S. A estrutura das } \\
\text { revoluções científicas. São Paulo, } \\
\text { S P: Ed. Perspectiva, } 1989 . \\
\text { MORAIS, R de. Filosofia } \\
\text { da ciência e da tecnologia. } \\
\text { Campinas: Papirus Editora, } 1988 . \\
\text { SANTOS, B. de SOUSA. Um } \\
\text { discurso sobre as ciências. Porto: } \\
\text { Ed. Afrontamento, 2002. } \\
\text { ESTEVES de V. M. J. } \\
\text { Pensamento sistêmico. O novo } \\
\text { paradigma da ciência. Campinas, } \\
\text { SP: Papirus, 2003. } \\
\text { SILVA FILHO, J. da. (Ed.). } \\
\text { Epistemologia e ensino de } \\
\text { ciências. Salvador: Arcádia, } \\
\text { 2002. }\end{array}$ \\
\hline
\end{tabular}

* Projeto Político de Curso de Química (2009). Documento solicitado na coordenação do curso, analisado em 21 de setembro de 2013.

Quadro 2 - Distribuição de disciplinas relacionada a Estudos Epistemológicos de Ciências no curso de Licenciatura em Ciências Biológicas (Integral e Noturno) da Universidade Federal de Goiás

\begin{tabular}{|c|c|c|c|c|}
\hline Curso & Disciplina & Período & Ementa & $\begin{array}{c}\text { Bibliografia } \\
\text { Básica }\end{array}$ \\
\hline $\begin{array}{l}\text { C i ê n c i a s } \\
\text { Biológicas - } \\
\text { Licenciatura } \\
\text { (Integral e } \\
\text { Noturno)* }\end{array}$ & $\begin{array}{l}\text { Filosofia da } \\
\text { Ciência (32h) } \\
-\quad \text { Núcleo } \\
\text { E s p e cíf i c o } \\
\text { Obrigatório }\end{array}$ & $\begin{array}{l}\text { Primeiro } \\
\text { (Diurno e } \\
\text { Noturno) }\end{array}$ & $\begin{array}{l}\text { Concepções gerais em } \\
\text { epistemologia: teoria, hipóteses e } \\
\text { modelos; Ciência e pseudociência; } \\
\text { observação e experimentação; } \\
\text { reducionismo; princípio antrópico; } \\
\text { complexidade; paradigmas } \\
\text { correntes em Biologia. }\end{array}$ & $\begin{array}{l}\text { Não havia } \\
\text { referenciais } \\
\text { bibliográficos } \\
\text { indicados. }\end{array}$ \\
\hline
\end{tabular}

* Projeto Político de Curso de Ciências Biológicas (2003). Disponível em: <http:// www.icb.ufg.br/uploads/99/original_Projeto_Pol_tico_Pedag_gico_do_Curso_de_Ci_ ncias_Biol_gicas.pdf>. Acesso em: 21 maio 2015.

Fonte: Elaboração dos autores. 
Do total de 78 acadêmicos entrevistados das Ciências Biológicas, 58\% pertenciam ao turno integral, $33 \%$ ao noturno e $9 \%$ não informaram qual frequentavam. Na Química, dos 43 sujeitos de pesquisa apenas 31\% eram do turno integral, ao passo que $69 \%$ eram do noturno. Essa diferença de porcentagens noturno/integral deve-se ao fato número de alunos matriculados em cada curso nos diferentes turnos.

No que se refere ao gênero dos estudantes entrevistados do curso de Ciências Biológicas, constatamos que $64 \%$ eram mulheres, $31 \%$ homens e $5 \%$ não forneceram a informação. Dos acadêmicos de Química 56\% eram homens, $42 \%$ mulheres e $2 \%$ não informaram. Percebemos com isso que a maior parte das entrevistadas era do gênero feminino, correspondendo a aproximadamente $56 \%$ do montante total de 121 pessoas. Deste total $40 \%$ eram homens e os outros $4 \%$ não informaram.

A análise global das informações provenientes da totalidade dos participantes, acadêmicos em formação docente nos cursos de Ciências Biológicas e Química, obtidas por meio da análise dos 78 desenhos para o primeiro e 43 desenhos para o segundo curso, permitiu realizar algumas considerações acerca do que estes alunos compreendem por Ciência e suas características. Ainda é oportuno destacar que alguns desenhos, além das imagens produzidas, apresentaram informações escritas, principalmente pensamentos e falas destacadas em balões veiculadas às personagens dos desenhos. Igualmente estas mensagens foram analisadas junto aos objetos representados nas imagens com o intuito de melhor compreendê-las. A seguir são apresentadas as categorias, subcategorias e percentuais obtidos a partir da análise dos desenhos.

A análise permitiu estabelecer três domínios principais: (1) Ciência representada pelo ambiente que a compõe; (2) Ciência representada pelos elementos integrantes à natureza específica de cada área e (3) Ciência representada pela imagem do cientista.

\section{Domínio Ciência Representada Pelo Ambiente que a Compõe}

Nesse primeiro domínio de análise, estabelecido como o ambiente em que a Ciência ocorre, foi possível reconhecer cinco categorias: laboratório e/ ou sala de aula; natureza (elementos naturais bióticos); natureza (elementos 
geofísicos - abióticos); natureza (elementos do universo) e elementos materiais (construções e/ou recursos tecnológicos). Dentro deste domínio detectamos diferenças entre os cursos (Tabela 1). Percebemos que a associação da Ciência a um ambiente específico, apesar de significativa para os dois cursos pesquisados, a porcentagem foi maior entre os estudantes de Ciências Biológicas (80,8\%) se comparado com os resultados da Química $(69,8 \%)$.

Entre as cinco categorias de ambientes observados, o ambiente "Laboratório e/ou Sala de Aula" (46,1\%), "Natureza - Elementos Naturais Bióticos" $(39,7 \%)$ e o "Natureza - Elementos do Universo" (32,1\%) foram mais bem representados pelos graduandos de Ciências Biológicas. Percebemos com isso que esses ambientes são para estes estudantes locais em que a Ciência se desenvolve (Figuras 1 e 2). Diferentemente do grupo investigado no curso de Química, os licenciandos do curso de Ciências Biológicas destacaram significativamente os elementos bióticos. Entendemos que este enfoque diferencial está relacionado aos objetos de estudo das Ciências Biológicas.

Figura 1 - Representação de ambiente laboratorial como sinônimo de Ciência, para o grupo investigado do Curso de Licenciatura em Química, Universidade Federal de Goiás
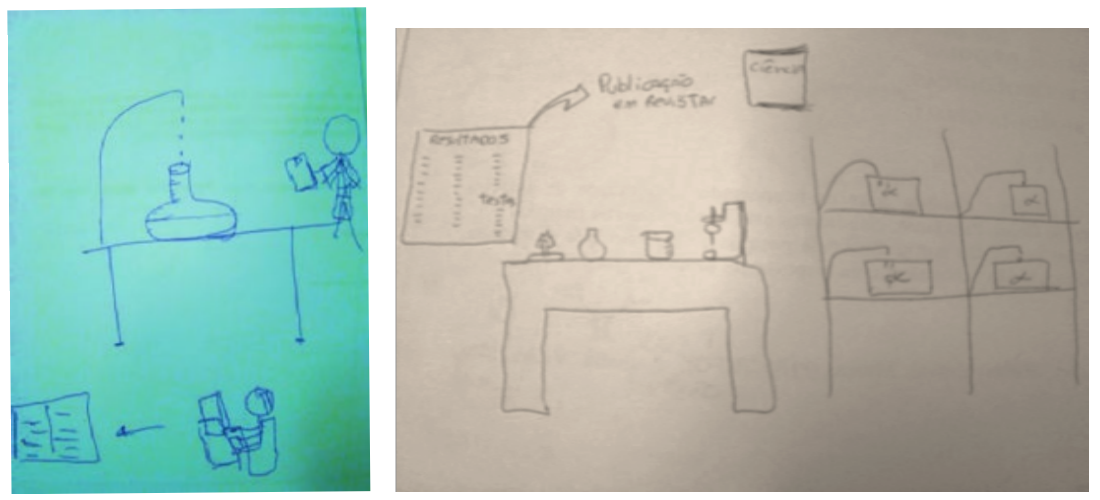

Fonte: Amostra de pesquisa 
Figura 2 - Representação de ambiente natural biótico e do ambiente laboratorial como sinônimo de Ciência, para o grupo investigado do Curso de Licenciatura em Biologia, Universidade Federal de Goiás
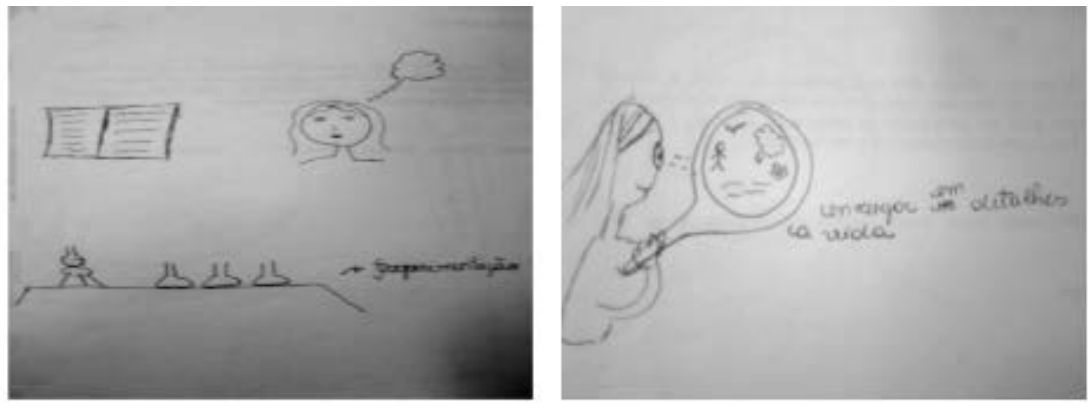

Fonte: Amostra de pesquisa

Para os acadêmicos de Química os ambientes mais frequentes foram o "Laboratório e Sala de Aula" (41,9\%) e "Natureza - Elementos do Universo" $(32,6 \%)$. Salientamos ainda que o ambiente "Natureza - Elementos Naturais Bióticos" (2,3\%) foi pouco evidenciado por estes discentes. Os acadêmicos do curso de Química pouco enxergam a relação deste ambiente com a Ciência.

Percebemos pelos resultados que, para os graduandos da Química, a Ciência é tida principalmente como uma atividade experimental quase específica de laboratório e que gera produtos finais, em que Tecnologia e Ciência quase sempre estão associadas. Em muitos momentos da história da Ciência o desenvolvimento da tecnologia possibilitou o avanço científico (GARRIDO; GONZÁLEZ, 2011). Podemos citar como exemplo a visualização de células animais e vegetais realizada por Anton Von Leeuwenhoek. Somente com o desenvolvimento do microscópio óptico foi possível a observação, descrição e análise das células, abrindo um novo horizonte para a produção do conhecimento científico. O aperfeiçoamento da tecnologia levou ao desenvolvimento do microscópio eletrônico (Ruska, 1987), o que proporcionou a ampliação das imagens, possibilitando a análise de texturas de materiais, desgastes químicos em substratos, a observação de macromoléculas, entre outros. 
Nesse contexto, cabe ressaltar que a relação Tecnologia-Ciência não é linear, no sentido que a técnica sempre precede e gera a Ciência. Para Solbes e Traver (1996), por meio da Ciência podem ser desenvolvidas diferentes técnicas de aplicação. Dessa forma, a relação entre as duas pode ser interpretada como circular, em que a "ciência permite produzir a tecnologia e esta permite o desenvolvimento da ciência, que, por sua vez, desenvolve a tecnologia" (MORIN, 2005, p. 63). Nos desenhos do curso de Química e de Ciências Biológicas não foi possível verificar a maneira como os acadêmicos compreendem esta inter-relação, sendo aspectos tecnológicos representados, como aquisição de produtos finais. A visão de Ciência expressa nos desenhos em ambos os cursos pode ser interpretada como linear (FERNÁNDEZ et al., 2002; GIL-PÉREZ et al., 2001), uma vez que oculta a complexidade e o processo de produção científica ao expressar quase que unicamente a relação que a Tecnologia gera Ciência.

Nessa altura nos indagamos: Existem diferenças significativas em relação aos componentes que estão presentes nos ambientes de "Laboratório e Sala de Aula" que apresentaram percentuais significativos para os dois cursos? Para responder a esta pergunta analisamos as subcategorias representadas nos desenhos que dizem respeito ao ambiente que a Ciência ocupa. Verificamos aqui convergências, em termos percentuais, na maior parte delas (Tabela 1).

Dentro da categoria "Laboratório e Sala de Aula", por exemplo, notamos como convergência mais representativa "Materiais, Vidrarias, Microscópio e Substâncias" com 34,6\% dos acadêmicos de Ciências Biológicas e 30,2\% dos da Química. Assim, em ambos os cursos pesquisados há uma relação significativa entre o fazer Ciência e o uso de laboratórios, o que evidencia a necessidade do uso de equipamentos laboratoriais e de substâncias químicas para o seu desenvolvimento. Observamos ainda a subcategoria "Experimentos" também apresenta uma proximidade dos percentuais, com 7,7\% das representações no curso de Ciências Biológicas e de 9,3\% para o da Química.

Na subcategoria "Artefatos para estudo" observamos que 24,4\% dos acadêmicos das Ciências Biológicas relacionam a Ciência ao estudo e à revisão bibliográfica, ao passo que apenas $14 \%$ dos estudantes da Química fazem a mesma relação. Como destaca Chalmers (1993), a teoria na produção do 
conhecimento científico ocupa lugar de relevo para filósofos da Ciência, tais como Karl R. Popper e Imre Lakatos. Seja a teoria precedendo a observação e experimentação (falsificacionismo) ou esta produzindo aquela (indutivismo), o relato histórico demonstra que o progresso na Ciência está intimamente ligado a essas relações (CHALMERS, 1993). O destaque dado à observação e experimentação e a escassa referência da teoria como anterior a esta revelam sinais de uma visão de Ciência empirista-indutivista e ateórica, bem como uma visão a-histórica e aproblemáticada na produção do conhecimento científico, como proposto por Fernández et al. (2002) e Gil-Pérez et al. (2001).

Já a categoria "Natureza - elementos naturais bióticos" destaca-se por apresentar um contraste alto no que se refere aos dados obtidos. Isto porque, como já ressaltamos, ela é mais representativa em Ciências Biológicas, ao passo que, para a Química, esta categoria é pouco representativa. A partir deste resultado podemos inferir que os elementos naturais bióticos não são contemplados dentro da visão de Ciência da maior parte dos graduandos de Química. As possíveis explicações para essa diferença podem estar relacionadas às formas de fazer Ciência e produzir conhecimento científico da Química e das Ciências Biológicas ao longo de sua constituição enquanto Ciência.

Em uma análise mais detalhada observamos que os vegetais - "Árvores e/ou Partes de Plantas" - e os animais, em especial "Animal Vertebrado", são os elementos mais representativos nessa categoria para o curso de Ciências Biológicas. Apesar de alguns desenhos retratarem elementos microscópicos percebemos que as subcategorias não alcançam os percentuais das plantas e animais. Compreendemos que essa forte imagem vinculada à Biologia ocorre em razão da classificação dos organismos vivos, objetos de pesquisa para a área. Os primeiros estudiosos do mundo vivo foram os naturalistas, que classificavam apenas os seres macroscópicos. As classificações eram feitas em Reino animal e Reino vegetal. Por mais que a tecnologia tenha possibilitado a exploração do universo microscópico nas últimas décadas e, consequentemente, mudado o sistema de classificação dos seres vivos (COPELAND, 1938; WHITTAKER, 
1969; WOESE; KANDLER; WHEELIS, 1990; MARGULIS; SCHWARTZ, 2001), a visão do biólogo como profissional que estuda plantas e animais ainda ocupa o cerne da sua atividade científica.

No que se refere à categoria "Natureza - Elementos do Universo", percebemos que os graduandos de Ciências Biológicas (32,1\%) e de Química $(32,6 \%)$ tiveram percentuais aproximados, existindo um predomínio de desenhos relacionados ao planeta Terra (18\% e 23,3\%, respectivamente). O elemento com maior discrepância nos dados é o "Sol”, com os estudantes de Ciências Biológicas o representando em maior número. Esta diferença ocorreu principalmente devido à associação existente do Sol como elemento integrante do ecossistema, sendo frequente nos desenhos dos estudantes de Biologia, relacionados à categoria "Natureza - Elementos Bióticos". Já entre os da Química o Sol foi representado associado a planetas e estrelas, que denominamos aqui como a subcategoria "Universo" (11,6\%).

A categoria "Natureza - Elementos geofísicos" foi pouco frequente entre os cursos de Ciências Biológicas e Química, bem como a "Elementos Materiais". Não houve uma associação das quatro perspectivas Ciência-Tecnologia-Sociedade-Ambiente para o domínio “Ambiente". Em geral os desenhos abordavam no máximo duas. Ciência e Tecnologia apareceram associadas, sobretudo no ambiente de Laboratório, distante do convívio social, geralmente associada a "Outras tecnologias". A interação Ciência e Sociedade apresentaram baixos percentuais. Isto revela uma dificuldade de ver a Ciência no cotidiano. A Sociedade também foi ilustrada como aquela que recebe uma divulgação/ transmissão do conhecimento científico ou o ensino da Ciência em questão. Percebemos, então, uma visão descontextualizada, individualista e socialmente neutra por parte desses licenciandos no que diz respeito à atividade científica (FERNÁNDEZ et al., 2002; GIL-PÉREZ et al., 2001). 
Tabela 1 - Representações de acadêmicos das Licenciaturas em Ciências Biológicas e Química da UFG acerca da Ciência como sinônimo de ambiente

\begin{tabular}{|c|c|c|c|c|c|c|c|}
\hline Domínio & Categoria & \multicolumn{2}{|c|}{ Subcategoria } & $\begin{array}{c}\text { Ciências } \\
\text { Biológicas }\end{array}$ & Química & Categoria & Domínio \\
\hline \multirow{20}{*}{$\begin{array}{l}\text { Ambiente } \\
\mathbf{8 0 , 8 \%}\end{array}$} & \multirow{6}{*}{$\begin{array}{c}\text { Laboratório } \\
\text { e Sala de } \\
\text { Aula } \\
46,1 \%\end{array}$} & \multicolumn{2}{|c|}{$\begin{array}{l}\text { Pia/Mesa/ } \\
\text { Bancada/ Baú }\end{array}$} & 15,3 & 4,7 & \multirow{6}{*}{$\begin{array}{c}\text { Laboratório } \\
\text { e sala de } \\
\text { aula } \\
41,9 \%\end{array}$} & \\
\hline & & \multicolumn{2}{|c|}{ Experimentos } & 7,7 & 9,3 & & \\
\hline & & \multicolumn{2}{|l|}{\begin{tabular}{|l|} 
Jaleco \\
\end{tabular}} & 3,8 & $\begin{array}{ll}--- \\
-\end{array}$ & & \\
\hline & & \multicolumn{2}{|c|}{\begin{tabular}{|l|} 
Materiais, \\
Vidrarias, \\
Microscópio e \\
Substâncias \\
\end{tabular}} & 34,6 & 30,2 & & \\
\hline & & \multicolumn{2}{|c|}{ Artefatos para estudo } & 24,4 & 14,0 & & \\
\hline & & \multicolumn{2}{|c|}{$\begin{array}{l}\text { Prancheta/ } \\
\text { Quadro - Associado à } \\
\text { sala e aula }\end{array}$} & 7,7 & 9,3 & & \\
\hline & \multirow{4}{*}{$\begin{array}{c}\text { Natureza - } \\
\text { Elementos } \\
\text { Naturais } \\
\text { Bióticos } \\
\text { 39,7\% }\end{array}$} & \multicolumn{2}{|c|}{\begin{tabular}{|l} 
Árvore e/ou Partes de \\
Plantas \\
\end{tabular}} & 38,5 & ---- & \multirow{4}{*}{$\begin{array}{c}\text { Natureza - } \\
\text { Elementos } \\
\text { Naturais } \\
\text { Bióticos } \\
2,3 \%\end{array}$} & $\begin{array}{c}\text { Ambiente } \\
69.8 \%\end{array}$ \\
\hline & & \multirow{3}{*}{$\begin{array}{c}\mathrm{A} \\
\mathrm{N} \\
\mathrm{I} \\
\mathrm{M} \\
\mathrm{A} \\
\mathrm{I} \\
\mathrm{S} \\
20,6 \%\end{array}$} & Vertebr. & 18,0 & 2,3 & & \\
\hline & & & Invertebr. & 5,1 & ---- & & \\
\hline & & & $\begin{array}{c}\text { Não } \\
\text { identif. }\end{array}$ & 1,3 & --- & & \\
\hline & \multirow{4}{*}{$\begin{array}{c}\text { Natureza - } \\
\text { Elementos } \\
\text { do Universo } \\
\mathbf{3 2 , 1 \%}\end{array}$} & \multicolumn{2}{|l|}{ Lua } & 2,6 & ---- & \multirow{4}{*}{$\begin{array}{c}\text { Natureza - } \\
\text { Elementos } \\
\text { do Universo } \\
\mathbf{3 2 , 6 \%}\end{array}$} & \\
\hline & & \multicolumn{2}{|c|}{\begin{tabular}{|l|} 
Planeta Terra \\
\end{tabular}} & 18,0 & 23,3 & & \\
\hline & & \multicolumn{2}{|l|}{ Sol } & 16,7 & 4,7 & & \\
\hline & & \multicolumn{2}{|c|}{ Universo } & 3,8 & 11,6 & & \\
\hline & $\begin{array}{l}\text { Natureza - } \\
\text { Elementos } \\
\text { Geofísicos } \\
\text { Abióticos }\end{array}$ & \multicolumn{2}{|c|}{$\begin{array}{l}\text { Chuva/ } \\
\text { cachoeira/rio }\end{array}$} & 7,7 & 2,3 & \multirow{2}{*}{\multicolumn{2}{|c|}{$\begin{array}{c}\text { Natureza - } \\
\text { Elementos } \\
\text { Geofísicos - } \\
\text { Abióticos } \\
\mathbf{2 , 3 \%}\end{array}$}} \\
\hline & & \multicolumn{2}{|l|}{ Nuvem } & 5,1 & 2,3 & & \\
\hline & Elementos & \multicolumn{2}{|c|}{\begin{tabular}{|l|} 
Carro/foguete \\
\end{tabular}} & 2,6 & 2,3 & \multirow{4}{*}{$\begin{array}{c}\text { Elementos } \\
\text { Materiais } \\
\mathbf{4 , 7 \%}\end{array}$} & \\
\hline & $\begin{array}{l}\text { Materiais } \\
\mathbf{9 , 0 \%}\end{array}$ & \multicolumn{2}{|c|}{$\begin{array}{l}\text { Construções em geral } \\
\text { (casas, edificios, entre } \\
\text { outros)* }\end{array}$} & 5,1 & 2,3 & & \\
\hline & & \multicolumn{2}{|c|}{ Para-raios } & --- & 2,3 & & \\
\hline & & \multicolumn{2}{|c|}{ Outras tecnologias } & 5,1 & 4,7 & & \\
\hline
\end{tabular}

* Laboratório e Sala de aula foram considerados juntos, por mesclarem os dois ambientes e por considerarmos o laboratório também um espaço de sala de aula.

Fonte: Elaboração dos autores. 


\section{Domínio Ciência Representada pelos Elementos Integrantes à Natureza Específica de Cada Área}

Neste domínio buscamos analisar as imagens, elencando as representações relacionadas ou não à natureza do conhecimento na área de Ciências: Química, Biologia, Física e/ou Matemática. Os dados podem ser observados na Tabela 2. Constatamos que os percentuais de "Elementos Específicos" nos cursos de Ciências Biológicas (83,3\%) e de Química $(83,7 \%)$ foram aproximados. Dentro deste domínio os elementos da "Biologia" foram mais representativos para os acadêmicos de Ciências Biológicas, bem como os elementos da "Química” para o curso de Química. O resultado era de se esperar, visto que esses elementos constituem-se como os principais objetos de estudo de cada curso.

Percebemos ainda que em termos gerais os acadêmicos de Ciências Biológicas ressaltam três áreas da Ciência de forma significativa. São elas: Biologia (60,3\%), Física (34,6\%) e Química (33,3\%). Já os estudantes de Química assinalaram com maior frequência apenas a Química $(51,2 \%)$ e a Física $(32,6 \%)$. Com base nesses dados, os estudantes de Química pouco evidenciaram os elementos específicos da Biologia (4,7\%). Ambos os cursos não contemplam elementos da Matemática de maneira representativa, uma vez que apenas 1,3\% dos graduandos de Ciências Biológicas e 4,7\% da Química destacaram elementos matemáticos. Nos desenhos percebemos que elementos da Matemática quando ilustrados eram colocados de forma marginal, com pouca ênfase e/ou como uma ferramenta. Concluímos pelos resultados que as concepções de $\mathrm{NdC}$ não refletem as múltiplas facetas da Ciência. São constituídas apenas de fragmentos isolados de sua composição.

Ao analisarmos as subcategorias relacionadas à categoria "Química" observamos que tanto em Ciências Biológicas quanto em Química houve um predomínio de "Vidrarias". Percebemos que o laboratório para ambas é caracterizado de maneira semelhante. Por mais que designemos aqui esta subcategoria a um elemento específico da Química, concordamos que as vidrarias são objetos pertencentes às diferentes áreas da Ciência, uma vez que são materiais de uso para experimentos na Biologia, Química e Física. Então, se considerarmos o uso de vidrarias, de forma mais ampla e não como elemento representativo somente 
da Química, os índices de representação de todas as categorias de elementos específicos aumentam consideravelmente. Para fins didáticos não faremos fazer essas contas, no entanto gostaríamos que ficasse claro ao leitor que não objetivamos com nossa análise fragmentar os elementos das áreas a ponto de ignorar as interfaces na apropriação do conhecimento científico.

O "Átomo" foi o segundo elemento mais representativo para a Química desta categoria (25,6\%), e pouco ilustrado nas Ciências Biológicas (3,8\%). Este dado corrobora com o que já foi discutido anteriormente: a diferença de objeto de estudo das duas áreas. Como é possível observar na Tabela 2, as subcategorias mais marcantes para os acadêmicos de Ciências Biológicas estão relacionadas ao "Grupo Vegetal" (38,5\%) e "Grupo Animal" (20,6\%). Detectamos ainda os percentuais para este curso nas subcategorias "ADN e Cromossomo" (17,9\%), "Microscópio e Lupa" (16,7\%) e "Elementos Celulares" (9\%), ao passo que na Química não foi feita nenhuma referência a estes.

Assim como na Biologia os grupos animal e vegetal remontam a sua história como Ciência, na Química algo semelhante acontece com o átomo. É a partir dos estudos de John Dalton (1808) e do resgate que este fez da ideia de átomo elaborado na Grécia antiga que permitiu anos depois, com a contribuição de muitos outros cientistas, a estruturação da Teoria Atômica, base da Química moderna (PINHEIRO; COSTA; MOREIRA, 2011). Queremos com isso demonstrar que os objetos de estudos que deram origem às áreas continuam como principais estruturas de representação. 
Tabela 2 - Representações de acadêmicos das Ciências Biológicas e Química da UFG acerca dos elementos específicos associados às áreas do conhecimento

\begin{tabular}{|c|c|c|c|c|c|c|}
\hline Domínio & Categoria & Subcategoria & \begin{tabular}{|l} 
Ciências \\
Biológicas
\end{tabular} & Química & Categoria & Domínio \\
\hline \multirow{12}{*}{$\begin{array}{c}\text { Elementos } \\
\text { Específicos } \\
\mathbf{8 3 , 3 \%}\end{array}$} & \multirow{4}{*}{$\begin{array}{l}\text { Química } \\
\mathbf{3 3 , 3 \%}\end{array}$} & Átomo & 3,8 & 25,6 & \multirow{4}{*}{$\begin{array}{l}\text { Química } \\
51,2 \%\end{array}$} & \multirow{12}{*}{$\begin{array}{c}\text { Elementos } \\
\text { Específicos } \\
\mathbf{8 3 , 7 \%}\end{array}$} \\
\hline & & \begin{tabular}{|l} 
Fórmula e \\
Molécula
\end{tabular} & 5,1 & 4,7 & & \\
\hline & & Medicamentos & 1,3 & ---- & & \\
\hline & & Vidrarias & 25,6 & 27,9 & & \\
\hline & \multirow{5}{*}{$\begin{array}{c}\text { Biologia } \\
60,3 \%\end{array}$} & \begin{tabular}{|l|} 
Microscópio e \\
Lupa
\end{tabular} & 16,7 & ---- & \multirow{5}{*}{$\begin{array}{c}\text { Biologia } \\
4,7 \%\end{array}$} & \\
\hline & & \begin{tabular}{|l|}
$\mathrm{ADN}$ e \\
Cromossomo \\
\end{tabular} & 17,9 & --- & & \\
\hline & & \begin{tabular}{|l|}
$\begin{array}{l}\text { E le me n t o s } \\
\text { celulares }\end{array}$ \\
\end{tabular} & 9,0 & ---- & & \\
\hline & & Grupo Animal & 20,6 & 2,3 & & \\
\hline & & Grupo Vegetal & 38,5 & 2,3 & & \\
\hline & \multirow[t]{2}{*}{$\begin{array}{l}\text { Física } \\
\mathbf{3 4 , 6 \%}\end{array}$} & \begin{tabular}{|l|} 
Elementos do \\
Universo \\
\end{tabular} & 34,6 & 32,6 & \multirow[t]{2}{*}{$\begin{array}{c}\text { Física } \\
32,6\end{array}$} & \\
\hline & & Fórmula & 1,3 & --- & & \\
\hline & \begin{tabular}{|c|} 
Matemática \\
$1,3 \%$ \\
\end{tabular} & Equação & 1,3 & 4,7 & $\begin{array}{c}\text { Matemática } \\
\mathbf{4 , 7 \%} \\
\end{array}$ & \\
\hline
\end{tabular}

Fonte: Elaboração dos autores.

\section{Domínio Ciência Representada pela Imagem do Cientista}

Ao analisarmos o último domínio, quanto à presença ou ausência do cientista, verificamos que 38,5\% dos licenciandos de Ciências Biológicas e 23,3\% dos de Química o desenharam associado à Ciência. Pela análise realizada concluímos que a Ciência para os cursos pesquisados aparece como um produto ou atividade relacionada ao cientista.

A Ciência como uma atividade coletiva quase não foi representada entre os dois cursos pesquisados, estando presente em apenas 1,3\% das representações dos acadêmicos das Ciências Biológicas. A atividade do cientista é vista quase como individual, assinalando assim uma visão individualista de Ciência como proposto por Fernández et al. (2002) e Gil-Pérez et al. (2001). 


\section{Considerações Finais}

Com o presente trabalho percebemos que embora os cursos possuam disciplinas com abordagem epistemológica, "Filosofia da Ciência" nas Ciências Biológicas e "Epistemologia da Ciência" no caso da Química, os acadêmicos representaram visões não adequadas de Ciência. Dessa forma, compreendemos que as disciplinas com abordagem epistemológica não estão sendo suficientes para (re)significar as concepções de Natureza da Ciência entre os estudantes nos cursos em questão. Tais disciplinas possuem uma carga horária diminuta diante do montante de carga total do curso. Nesse sentido, defendemos a necessidade de promover reflexões que problematizem a $\mathrm{NdC}$ em suas múltiplas formas de fazer e produzir, não só nessas disciplinas, mas em toda a Graduação.

As concepções de $\mathrm{NdC}$ dos estudantes foram associadas aos objetos de estudo de cada área do conhecimento (Ciências Biológicas e Química), o que é compreensível, contudo ressaltamos que na condição de futuros professores de Ciências é necessário possuir uma visão ampla sobre as diferentes formas de fazer e produzir Ciência. Caso o professor atenha-se apenas a uma área, por exemplo, a Química, que possui uma característica mais experimental, ele pode correr o risco de transmitir visões incompletas e não adequadas do que seja a Ciência em seu sentido mais amplo.

O presente estudo abre possibilidades para futuros trabalhos, uma vez que diferentes questionamentos surgiram durante sua execução. Ele nos permitiu observar aspectos acerca das concepções de $\mathrm{NdC}$ dos acadêmicos de Ciência que não estão na superficialidade aparente e que por uma série de problemáticas não podem ser exploradas pelos professores formadores de disciplinas de caráter epistemológico. Esperamos com nossos resultados e reflexões possam contribuir para discussões na pesquisa de concepções de $\mathrm{NdC}$ e sobre o pensar o fazer e produzir Ciência na formação de professores de Ciências.

\section{Referências}

BRICKHOUSE, N. W. The teaching of the philosophy of science in secondary classrooms: case studies of teachers' personal theories. International Journal of Science Education, v. 11, n. 4 , p. 437-449, 1989. 
BÖER, N. Educação ambiental em escolas de $1^{\circ}$ grau. 1993. Dissertação (Mestrado) UFSM, Santa Maria, 1993.

Educação ambiental e visões de mundo: uma análise pedagógica e epistemológica. 2007. Tese (Doutorado) - Florianópolis: UFSC, 2007.

CACHAPUZ, A. et al. (Org.). A necessária renovação do ensino de ciências. 2 ed. São Paulo: Cortez, 2011.

CARVALHO, I. C. M. Educação ambiental e formação do sujeito ecológico. 5. ed. São Paulo: Cortez, 2011.

CHALMERS, A. F. O que é ciência afinal? São Paulo: Brasiliense, 1993.

COPELAND, H. F. The kingdoms of organisms. The Quarterly Review of Biology, v. 13, n. 4, p. 383-420, 1938.

DALTON, J. A New System of Chemical Philosophy. Manchester: S. Russell for R. Bickerstaff, Part 1, 1808.

FEYERABEND, P. K. Against Method: outline of an anarchistic theory of knowledge. Londres: New Left Books, 1975.

FERNÁNDEZ, I. et al. Visiones deformadas de la Ciencia transmitidas por la enseñanza. Enseñanza de las Ciencias, v. 20, n. 3, p. 477-488, 2002. Disponível em: <http://ddd. uab.cat/pub/edlc/02124521v20n3p477.pdf>. Acesso em: 6 abr. 2016.

GARRIDO, G. B.; GONZÁLEZ, M. B. Microscopio de Leeuwenhoek. Revista Eureka sobre Enseñanza e divulgación de las Ciencias, n. 8, p. 487-490, 2011.

GIL-PÉREZ, D. et al. Para uma imagem não deformada no ensino de Ciências. Revista Ciência e Educação, Bauru, v. 7, n. 2, p. 125-153, 2001.

GIL-PÉREZ, D.; VILCHES, A.; FERREIRA-GAUCHÍA, C. Over coming the Oblivion of Technology in Physics Education. International Comission on Physics Education (Conference), 2008. Disponível em: <https://web.phys.ksu.edu/icpe/publications/teach2/ Gil-perez.pdf>. Acesso em: 6 abr. 2016.

KUHN, T. S. The Structure of Scientific Revolutions. Chicago: University of Chicago, 1970.

LAKATOS, I. Criticism and the Growth of Knowledge. Cambridge: Cambridge University Press, 1974.

LEDERMAN, N. G. Students' and Teachers' Conceptions of Nature of Science: a review of research. Journal of Research in Science Teaching, v. 29, n. 4, p. 331-359, 1992.

MARGULIS, L.; SCHWARTZ, K. V. Cinco reinos. Um guia ilustrado dos filos da vida na Terra. Rio de Janeiro: Guanabara-Koogan, 2001. 497 p. 
MESQUITA, N. As visões de ciência nos desenhos animados Jimmy Nêutron e O Laboratório de Dexter. 2006. Dissertação (Mestrado) - Universidade Federal de Goiás, Goiás, 2006.

MESQUITA, N. S.; SOARES, M. H. F. B.Visões de ciência em desenhos animados: uma alternativa para o debate sobre a construção do conhecimento científico em sala de aula. Ciência e Educação, Bauru, v. 14, n. 3, p. 417-429, 2008.

MORIN, E. Ciência com consciência. Tradução Maria D. Alexandre e Maria Alice Sampaio Dória. Rio de Janeiro: Bertrand Brasil, 2005.

OLIVEIRA, F. B. Conversa com cientistas: uma atividade para transformar a visão de Ciência de professores de ciências. Genética na Escola, v. 8, n. 1, p. 4-9, 2013.

PETRUCCI, D.; DIBAR URE, M. C. Imagen de la Ciencia en alumnos universitarios: una revisión y resultados. Enseñanza de las Ciencias, v. 2, n. 19, p. 217-229, 2001.

PINHEIRO, L. A.; COSTA, S. S. C.; MOREIRA, M. A. Do átomo grego ao modelo padrão: os indivisíveis de hoje. Porto Alegre: Instituto de Física da UFRGS, 2011. (Texto de Apoio ao Professor de Física).

POPPER, K. R. Conjectures and Refutations. Londres: Routledge and Kegan Paul, 1969. REISS, M. J. The relationship between evolutionary biology and religion. Evolution, v. 63, n. 7, p. 1.934-1.941, 2009.

RUSKA, E. The Development of the Electron Microscope and of Electron Microscopy. Bioscience Reports, v. 7, p. 607-629, 1987.

SOLBES, J.; TRAVER, M. J. La Utilización de la Historia de las Ciencias en La Enseñanza de la Física y la Química. Enseñanza de las Ciencias, v. 14, n. 1, p. 103-112, 1996.

UNIVERSIDADE FEDERAL DE GOIÁS. UFG. Projeto Político Pedagógico do Curso de Ciências Biológicas. Goiânia, GO, 2003. Disponível em: <http://www.icb.ufg.br/ uploads/99/original_Projeto_Pol_tico_Pedag_gico_do_Curso_de_Ci_ncias_Biol_gicas. pdf>. Acesso em: 21 maio 2015.

. UFG. Projeto Político-Pedagógico do Curso de Química. Goiânia, GO, 2009. Disponível com Coordenação do Curso, analisado em 21 de setembro de 2014.

WHITTAKER, R. H. New concepts of kingdoms of organisms. Science, v. 163, p. 150$163,1969$.

WOESE, C. R.; KANDLER, O.; WHEELIS, M. L. Towards a natural system of organisms: proposal for the domains Archaea, Bacteria, and Eucarya. Proceedings of the National Academy of Sciences of the United States of America, v. 87, p. 4.576-4.579, 1990.

Recebido em: 28/4/2016

Aceito em: $1 \% / 9 / 2016$ 